\title{
Plant polyphenols as electron donors for erythrocyte plasma membrane redox system: validation through in silico approach
}

\author{
Rajesh Kumar Kesharwani ${ }^{1}$, Durg Vijay Singh ${ }^{2}$, Krishna Misra ${ }^{1}$ and Syed Ibrahim Rizvi ${ }^{3^{*}}$
}

\begin{abstract}
Background: The plasma membrane redox system (PMRS) has extensively been studied in erythrocytes. The PMRS plays an important role in maintaining plasma redox balance and provides a protective mechanism against oxidative stress. Earlier it was proposed that only NADH or NADPH provided reducing equivalents to PMRS; however, now it is acknowledged that some polyphenols also have the ability to donate reducing equivalents to PMRS.

Methods: Two different docking simulation softwares, Molegro Virtual Docker and Glide were used to study the interaction of certain plant polyphenols viz. quercetin, epigallocatechin gallate, catechin epicatechin and resveratrol with human erythroyte NADH-cytochrome b5 reductase, which is a component of PMRS and together with the identification of minimum pharmacophoric feature using Pharmagist.

Results: The derived common minimum pharmacophoric features show the presence of minimum bioactive component in all the selected polyphenols. Our results confirm wet lab findings which show that these polyphenols have the ability to interact and donate protons to the Human NADH-cytochrome b5 reductase.

Conclusion: With the help of these comparative results of docking simulation and pharmacophoric features, novel potent molecules can be designed with higher efficacy for activation of the PMRS system.
\end{abstract}

Keywords: In Silico, QSAR, Polyphenols, Pharmacophoric, Docking simulation, Glide, Molegro Virtual Docker

\section{Background}

The property of erythrocytes to reduce membrane impermeant anions was first reported by Orringer and Roer [1]. Later researches established the existence of trans-membranous NADH dehydrogenases in several other cell types [2,3]. Evidence is now clear for the presence of a trans-plasma membrane electron transport or plasma membrane redox system (PMRS) in all organisms including bacteria, yeast, animals and plants [4,5]. It is accepted that PMRS is involved in transferring reducing equivalents from intracellular donors to extracellular acceptors mainly oxidized ascorbate. In this way the PMRS helps the cells to respond to changes in redox potential thereby

\footnotetext{
* Correspondence: sirizvi@gmail.com

${ }^{3}$ Department of Biochemistry, University of Allahabad, Allahabad 211002, India

Full list of author information is available at the end of the article
}

regulating a variety of physiological functions including cell metabolism, ion channels, growth and death [6,7].

The PMRS has extensively been studied in erythrocytes basically due to the fact that erythrocytes lack mitochondria and PMRS is the only mechanism for trans-plasma membrane electron transport. Importantly, erythrocytes encounter a variety of oxidants in the blood during their life span. Recent reports show that erythrocyte PMRS plays an important role in providing protection against oxidative stress during human aging [8,9] and in type 2 diabetes mellitus [10]. The basic structure of PMRS includes three major entities: the intracellular electron donor species, electron carrier proteins and oxidoreductases and extracellular electron acceptors. An important enzyme of PMRS in erythrocyte is the cytochrome $b_{5}$ reductase (EC 1.6.2.2).

Cytochrome $b_{5}$ reductase is encoded by the CYB5R3 locus located on chromosome 22q 13-qter (287). The 
tertiary folding structure of human cyt $b_{5}$ red, revealed by X-ray crystallography shows similarity with other flavin-linked oxido reductases such as ferredoxin: NADP +reductase and phthalate dioxygenase reductase [11]. Cyt $b_{5}$ reductase contains two functional lobes: a flavin adenine dinuceotide FAD-binding amino terminal domain (residues 33-147) and NADH-binding carboxyl end domain (residues 148-170). The two domains are linked by a hinge region (residues 148-170), which is critical for the protein conformation and enzymatic activity. Cyt $b_{5}$ red. catalyses one-electron reduction reactions in association with FAD and cytochrome $b_{5}$.

In erythrocytes, cytochrome b5 reductase primarily helps in maintaining hemoglobin in its reduced state

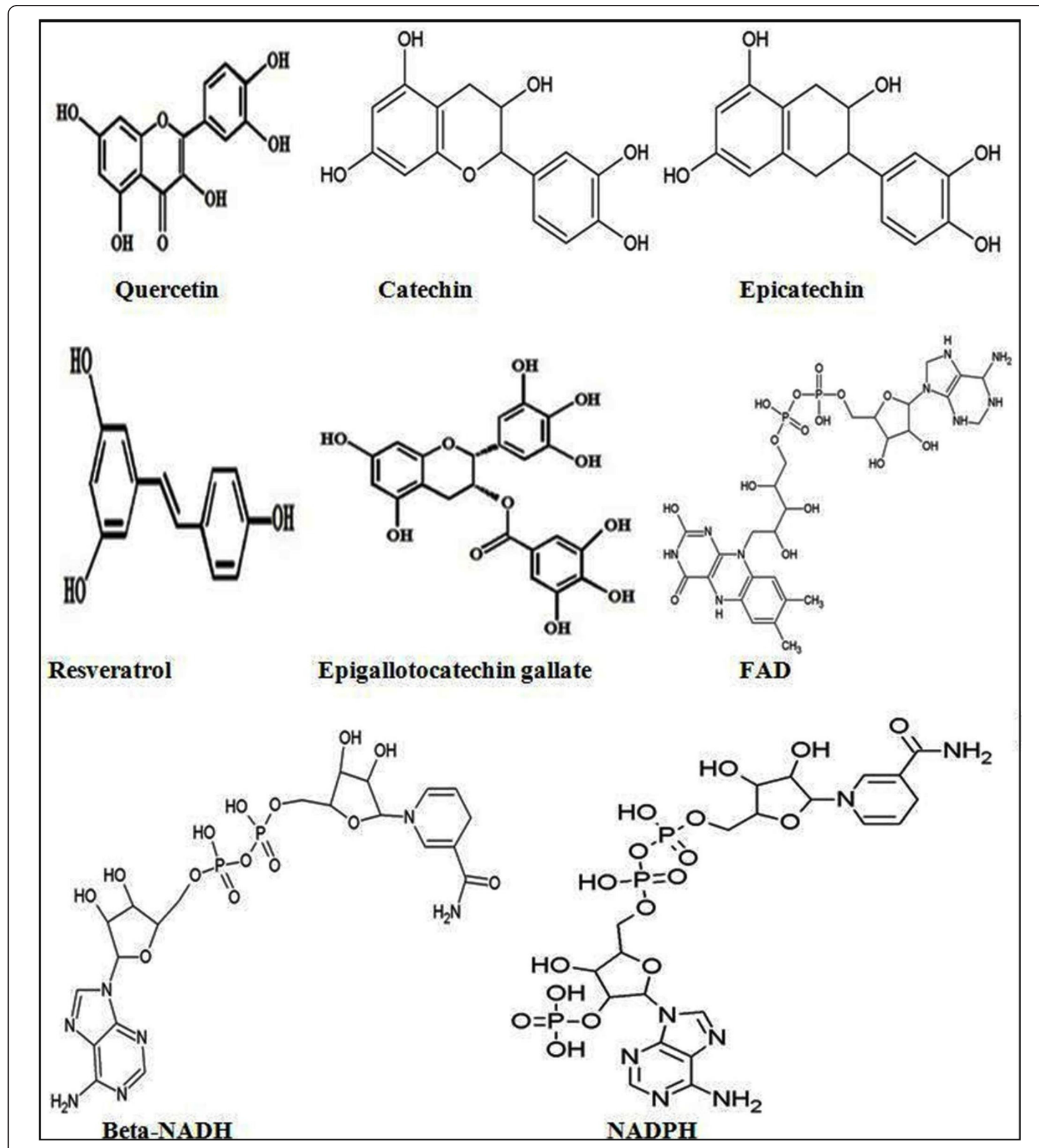

Figure 1 2-D structure of selected polyphenols (quercetin, catechin, epicatechin, resveratrol and EGCG), FAD, beta-NADH and NADPH. 
Table 1 Comparative docking simulation result of selected polyphenols, NADPH and beta-NADH with Human NADH-cytochrome b5 reductase together with FAD, ligand from X-ray Crystallized data of protein data bank (1umk.pdb) using MVD

\begin{tabular}{llll}
\hline Serial Number & Ligands & MoleDockScore & H-bonding energy \\
\hline 1. & FAD & -232.638 & -20.532 \\
2. & NADPH & -209.954 & -13.985 \\
3. & beta-NADH & -208.235 & -13.506 \\
4. & EGCG & -131.595 & -9.012 \\
5. & Quercetin & -113.611 & -10.033 \\
6. & Catechin & -110.472 & -9.063 \\
7. & Epicatechin & -102.952 & -14.638 \\
8. & Resveratrol & -102.074 & -10.272 \\
\hline
\end{tabular}

and also plays a crucial role in reducing extracellular ascorbate-free radical to ascorbate. Earlier it was proposed that only NADH or NADPH provided reducing equivalents to PMRS, however, now it is acknowledged that some polyphenols and ascorbate also have the ability to donate reducing equivalents to PMRS. It is now known that resveratrol, quercetin, myricetin, and epigallocatechin gallate (EGCG) may be taken up by erythrocytes from the plasma and actively promote PMRS activity $[12,13]$. In view of the important role of PMRS during aging and the emerging opinion that activation of erythrocyte PMRS may be an effective anti-aging strategy [14], this study was undertaken to determine the comparative molecular binding indices of some polyphenols (quercetin, catechin, epicatechin, resveratrol and EGCG together with FAD, NADPH and NADH (Figure 1) with an important component of erythrocyte PMRS, the cytochrome b5 reductase, through computational docking simulation using Molegro Virtual Docker (MVD) [15], Glide module (supplied by Schrödinger suite) [16] and ligand-based pharmacophoric feature derivation using PharmaGist server [17].

\section{Methods}

\section{Protein structure and preparation}

Three-dimensional X-ray crystallized structure of Human NADH-cytochrome b5 reductase (PDB: 1UMK, resolution $=1.75 \AA$ ) was downloaded from the Protein Data Bank $[18,19]$. The downloaded protein has single chain A with 275 residues together with FAD-binding region and contains bound FAD as a ligand molecule. It also contains 753 water molecules of crystallization. The protein structure was prepared using the protein preparation module of Schrödinger software [20]. The co-crystallized ligands and water molecules were removed. Some residues and side chain atom are missing in crystallized structure of protein that was modeled using Prime 2.2.108 followed by
Table 2 Comparative docking simulation result of selected polyphenols, FAD, NADPH and beta-NADH with Human NADH-cytochrome b5 reductase using Glide docking simulation software

\begin{tabular}{llllll}
\hline $\begin{array}{l}\text { Serial } \\
\text { number }\end{array}$ & Ligands & GScore & $\begin{array}{l}\text { Lipophilic } \\
\text { EvdW }\end{array}$ & HBond & Electro \\
\hline 1 & FAD & -12.18 & -5.07 & -2.14 & -0.71 \\
2 & NADPH & -10.86 & -4.45 & -2.13 & -0.68 \\
3 & beta-NADH & -10.48 & -4.43 & -1.72 & -0.79 \\
4 & EGCG & -9.10 & -4.13 & -1.33 & -0.51 \\
5 & Catechin & -7.83 & -4.41 & -1.75 & -0.95 \\
6 & Quercetin & -7.82 & -4.19 & -1.58 & -0.94 \\
7 & Epicatechin & -7.57 & -3.12 & -1.33 & -1.07 \\
8 & Resveratrol & -4.29 & -3.8 & -1.5 & -0.54 \\
\hline
\end{tabular}

Where GScore: It is GlideScore called as Docking Score

LipophilicEvdW: It is term derived from hydrophobic grid potential and fraction of the total protein-ligand Van der Waals energy; HBond: Hydrogen-bonding term.

Electro: This term represents Electrostatic rewards

refinement of the protein structure. The final modeled protein was taken as receptor protein and found the most suitable-binding site using sitemap script of Schrödinger. On the basis of priority of site, FADbinding site has been selected for docking with the FAD, NADPH, beta-NADH, catechin, quercetin, epicatechin, EGCG and resveratrol.

\section{Ligands structure preparation}

All the selected ligands were assigned an appropriate bond order using the LigPrep 2.4.107 script and converted to .mae format (Maestro, Schrödinger, Inc.) followed by optimization by means of the OPLS_2005 force field [21].

\section{Experimental}

\section{Docking study with MVD}

It is an automated docking software with fast processing. The preparation of selected polyphenols and protein were done using default parameters, which automatically adds the missing hydrogen atoms. The software has module to create surface over receptor molecule and to give possible binding site for its activity. The active site region of receptor Human NADH-cytochrome b5 reductase protein was chosen for docking, which is already known from literature with the selected polyphenols. It gives ten conformations for each ligand and returns five outputs with MoleDockScore and other thermodynamically calculated values. The MoleDockScore is an anonymous value on which we have to suggest the best docked ligand with its conformation. It also shows hydrogen bond information together with other thermodynamic values, which suggest the formation of stable complex between ligand and receptor molecule [15]. 
Table 3 Human NADH-cytochrome b5 reductase protein residues interact with selected polyphenols, NADPH and betaNADH using MVD (highlighted residues are involved in H-bonding interaction with ligands) and FAD from X-ray Crystallized data of protein data bank

\begin{tabular}{|c|c|c|c|}
\hline $\begin{array}{l}\text { Serial } \\
\text { Number. }\end{array}$ & ligands & Interacting residues of receptor Human $\mathrm{NADH}$-cytochrome b5 reductase & $\begin{array}{l}\text { No. of } \mathrm{H} \text {-bond } \\
\text { interaction }\end{array}$ \\
\hline 1. & FAD & $\begin{array}{l}\text { Arg91, Pro92, Tyr93, Val108, Ile109, Lys110, Tyr112, Phe113, Phe120, Gly123, Gly124, Lys125, } \\
\text { Ser127, Thr181, Thr184 }\end{array}$ & 13 \\
\hline 2. & NADPH & $\begin{array}{l}\text { His77, Arg91, Pro92, Tyr93, Thr94, Val108, Ile109, Try112, His117, Phe120, Gly123, Ser127, Thr181, } \\
\text { Thr184, Pro185 }\end{array}$ & 12 \\
\hline 3. & beta-NADH & $\begin{array}{l}\text { Arg91, Pro92, Tyr93, Thr94, Val108, Ile109, Lys110, Phe113, His117, Gly123, Gly124, Lys125, } \\
\text { Thr181, Thr184 }\end{array}$ & 10 \\
\hline 4. & EGCG & Arg91, Tyr93, Tyr112, Phe113, His17, Phe120, Gly123, Gly124, Lys125 & 5 \\
\hline 5. & Catechin & His77, Pro92, Tyr93, Thr94, Val108, Ile109, Thr184, Pro185, Phe300 & 6 \\
\hline 6. & Quercetin & His77, Pro92, Tyr93, Thr94, Val108, Ile109, Thr181, Thr184, Cys273, Phe300 & 7 \\
\hline 7. & Epicatechin & Pro92, Tyr93, Thr94, Val108, Ile109, Lys110, Thr181, Thr184, Pro185, Phe300 & 8 \\
\hline 8. & Resveratrol & His77, Pro92, Tyr93, Thr94, Val108, Ile109, Lys110, Thr181, Thr184, Pro185, Phe300 & 5 \\
\hline
\end{tabular}

Where MoleDock Score is molegro docking scoring function or Energy Score $\left(\mathrm{E}_{\mathrm{Score}}\right)$

\section{Docking study with glide}

The Protein ligand docking studies were performed using Maestro 9.1.107. Default parameters were selected with Glide Extra Precision (XP Glide), version 4.5.19. After the complete preparation of ligands and protein for docking, receptor-grid files were generated. For running the grid generation module we have scaled van der Waal radii of receptor atoms by $1.00 \AA$ with a partial atomic charge of 0.25 . A grid box of size $25 \times 25 \times 25$ $\AA$ with coordinates $\mathrm{X}=37.955433, \mathrm{Y}=-6.749032$ and $\mathrm{Z}$ $=39.920372$ was generated at the centroid of the FADbinding site predicted by sitemap script of Schrödinger suite 10.0. After the formation of receptor-grid file, flexible ligands with rigid receptor docking were performed. Glide generates conformations internally and passes these through a series of filters. The final energy evaluation is done with GlideScore and a single best pose is generated as the output for a particular ligand [16].

Pharmacophoric study

It is highly efficient method for the derivation of a minimum pharmacophoric features which is spatial arrangement of physico-chemical properties in a set of ligand, essential for the interaction with a specific receptor. It takes three dimensional structure of set of ligands as an input to multiply align flexible ligands in a deterministic manner and to focus on the input ligands. It searches shared large common substructure for the detection of both outer molecules and alternative binding modes and finally derived pharmacophoric features shared by a large number of ligand molecules as an output [17].

\section{Results and discussion}

The binding site cavity detection and docking simulation was performed by using two different docking softwares, namely MVD and Glide simulation module (supplied by Schrödinger suite) for the selected polyphenols together with FAD NADPH and beta-NADH at Human NADHcytochrome b5 reductase.

The results obtained using MVD and Glide, shown in terms of MoleDockScore; H-bonding energy and Glide score; LipophilicEvdW enrgy; HBond energy; Electro energy respectively are given in Table 1 and 2 .

The comparative result of docking simulation given in Tables 3 and 4, shows active site residues and proves

Table 4 Human NADH-cytochrome b5 reductase protein residues interact with selected polyphenols, NADPH, betaNADH using Glide docking simulation software (highlighted residues are $\mathbf{H}$-bonding interacting residues) and FAD from X-ray Crystallized data of protein data bank

\begin{tabular}{llll}
\hline $\begin{array}{l}\text { S. } \\
\text { No. }\end{array}$ & ligands & Interacting residues of receptor Human NADH-cytochrome b5 reductase & $\begin{array}{l}\text { No. of H-bond } \\
\text { interaction }\end{array}$ \\
\hline 1. & FAD & $\begin{array}{l}\text { Arg91, Pro92, Tyr93, Thr94, Val108, Ile109, Lys110, Phe113, Phe120, Gly123, Gly124, Lys125, Met126, } \\
\text { Ser127, Gly179, Gly180, Thr181, Thr184 }\end{array}$ & 17 \\
2. & NADPH & Thr94, Lys110, Try112, His117, Gly179, Gly180, Thr181, Thr184, Gln210, Cys273, Pro275 & 8 \\
3. & beta-NADH & Tyr93, Lys110, Tyr112, Gly179, Gly180, Thr181, GIn210, Asp239, Phe251, Val252, Pro275 & 8 \\
4. & EGCG & His117, Asn209, Gln210, Asp239, Phe251, Met278 & 4 \\
5. & Catechin & Lys110, Tyr112, Gly180, Ala208, Asn209, Gln210, Phe251, Val252, Pro275 & 6 \\
6. & Quarcetin & Lys110, Tyr112, Ala208, Asn209, Asp239, Phe251 & 4 \\
7. & Epicatechin & Lys110, Tyr112, Gly180, Ala208, Gln210, Asp239, Phe251, Val252, Pro275 & 7 \\
8. & Reserveratrol Lys110, Tyr112, Ala208, Gln210, Phe251, Val252 & 3 \\
\hline
\end{tabular}




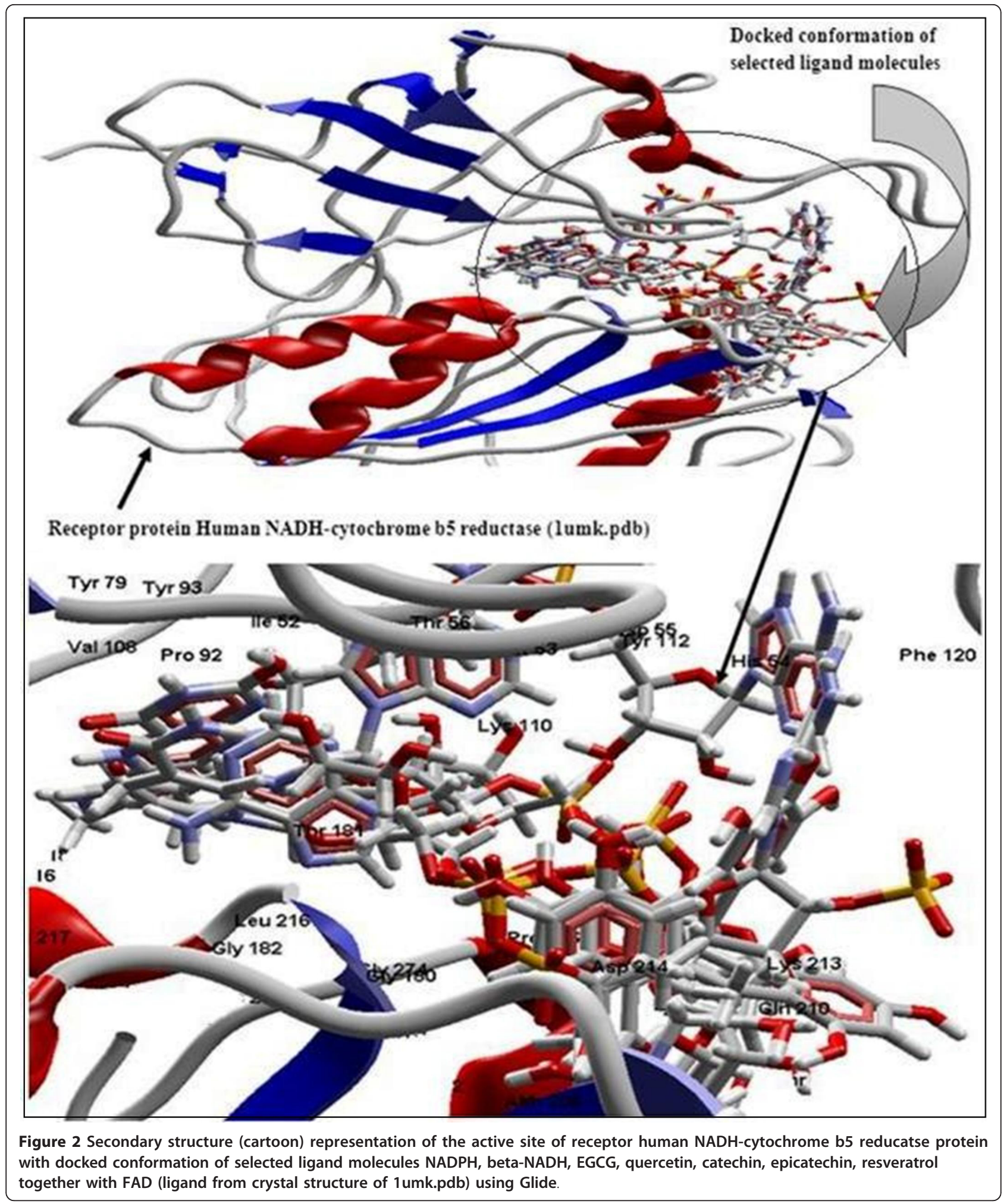

that a number of hydrogen bonds are involved in interaction between selected polyphenols, FAD, NADPH and beta-NADH with the receptor Human NADH-cytochrome b5 reductase.
The binding affinity of selected polyphenols, NADPH, beta-NADH and FAD at the active site of Human NADH-cytochrome b5 reductase using MVD and Glide in decreasing order is: $\mathrm{FAD}>\mathrm{NADPH}>$ beta- 


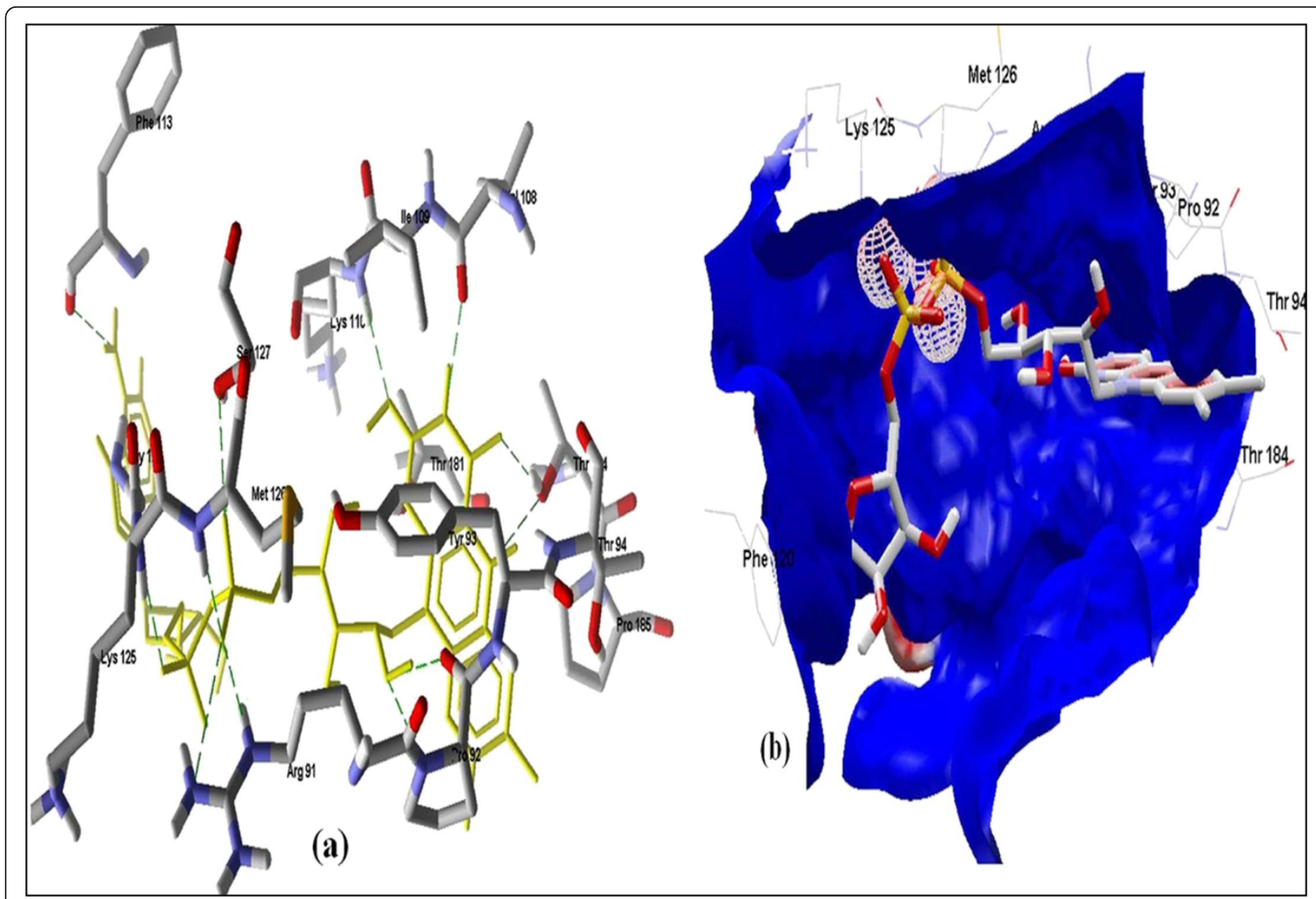

Figure 3 Docked conformation of hydrogen bonding view and 3.b with Electrostatic interaction of FAD with interacting amino acids of human NADH-cytochrome b5 reducatse protein at the active site cavity.

NADH $>$ EGCG $>$ quercetin $>$ catechin $>$ epicatechin $>$ resveratrol and $\mathrm{FAD}>\mathrm{NADPH}>$ beta-NADH $>\mathrm{FAD}>\mathrm{NADPH}>-$ beta-NADH $>$ EGCG $>$ catechin $>$ quercetin $>$ epicatechin $>-$ resveratrol respectively.

The Figure 2 of Glide docking simulation results shows low energy bound conformation of selected polyphenols, NADPH, beta-NADH and together with FAD (ligand from crystal structure of PDB:1UMK) at the active site of Human NADH-cytochrome b5 reductase. The low energy bound conformation of selected ligands shows hydrogen bonding and electrostatic interactions as shown in Figure $3(\mathrm{a}, \mathrm{b}), 4(\mathrm{a}, \mathrm{b}), 5(\mathrm{a}, \mathrm{b}), 6(\mathrm{a}, \mathrm{b}), 7$ $(\mathrm{a}, \mathrm{b}), 8(\mathrm{a}, \mathrm{b}), 9(\mathrm{a}, \mathrm{b})$ and $10(\mathrm{a}, \mathrm{b})$ for FAD, NADPH, beta-NADH, epigallocatechin gallate, catechin, quarcetin, epicatechin and resveratrol respectively.

Figure 2 of Glide docking simulation results shows low energy bound conformation of selected polyphenols, $\mathrm{NADPH}$, beta-NADH, and together with FAD (ligand from crystal structure of PDB:1UMK) at the active site of Human NADH-cytochrome $b_{5}$ reductase. The low energy bound conformation of selected ligands shows hydrogen bonding and electrostatic interactions as shown in Figures 3a, b, 4a, b, 5a, b, 6a, b, 7a, b, 8a, b, 9a, b, and 10a, b for FAD, NADPH, beta-NADH, EGCG, catechin, quarcetin, epicatechin, and resveratrol, respectively

Computational methods provide aids for not only designing and interpretation of hypothesis-driven experiments in the field of drug discovery research but may also be used to compare in vitro results for rapid generation of new hypotheses. The binding affinity was higher for FAD because it is a natural ligand of the receptor protein having highest number of hydrogen bonds. The formation of hydrogen bonds provides additional force to stabilize the ligand-protein complex required for the activity of the Human NADH-cytochrome b5 reductase. The results obtained using two different docking simulation softwares were compared and their findings were common, which also strongly supports our in silico findings. An analysis of pharmacophoric features of the docked conformation for all the selected polyphenols, NADPH, beta-NADH and FAD, in the study provided the minimum common phormacophoric features shown in Figure 11, which include one aromatic ring, two donor atoms and one acceptor atom derived from PhrmaGist server [17]. The presence of 


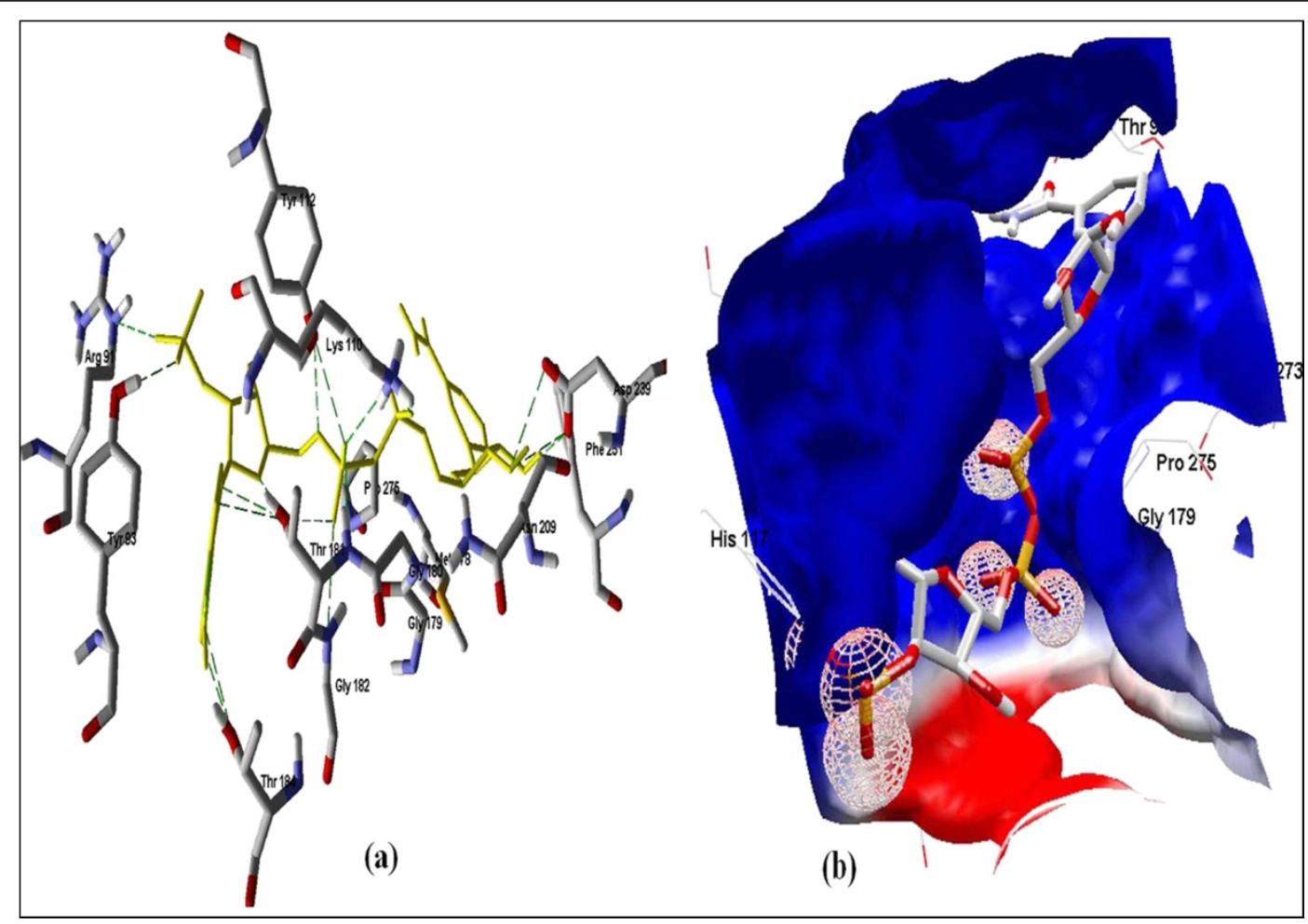

Figure 4 Docked conformation of hydrogen bonding view and 4.b with Electrostatic interaction of NADPH with interacting amino acids of human NADH-cytochrome b5 reducatse protein at the active site cavity.

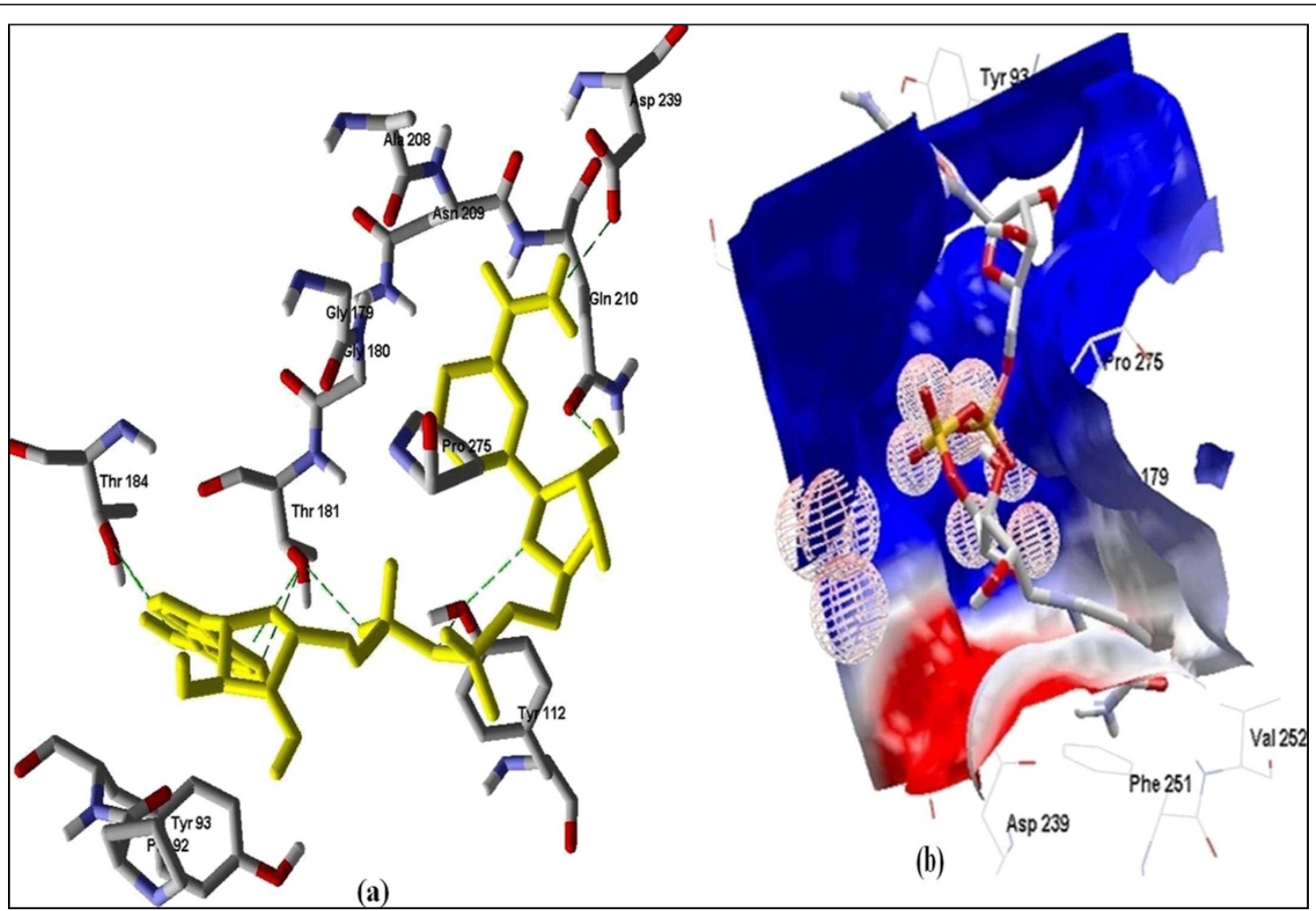

Figure 5 Docked conformation of hydrogen bonding view and 5.b with Electrostatic interaction of beta-NADH with interacting amino acids of human NADH-cytochrome b5 reducatse protein at the active site cavity 


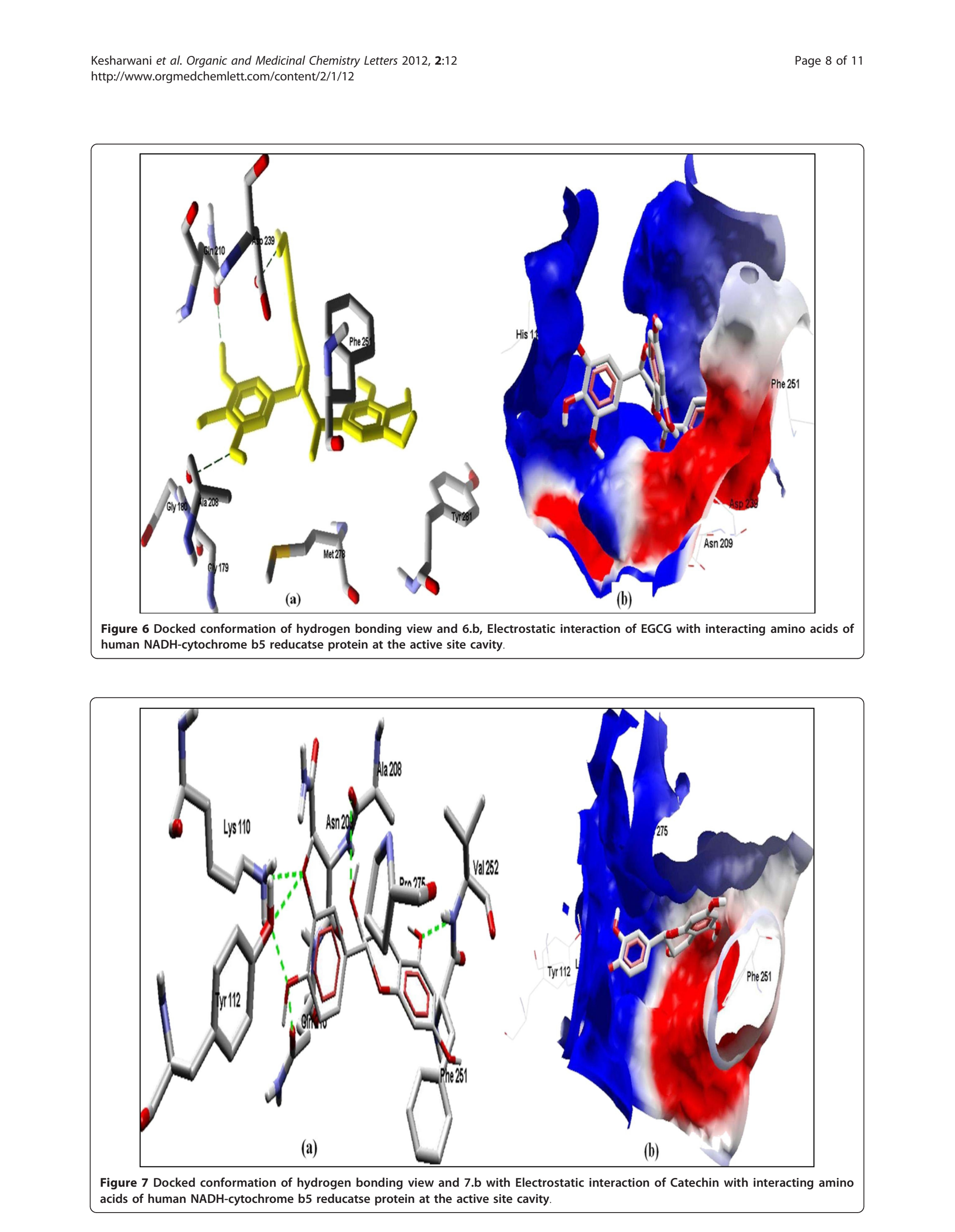




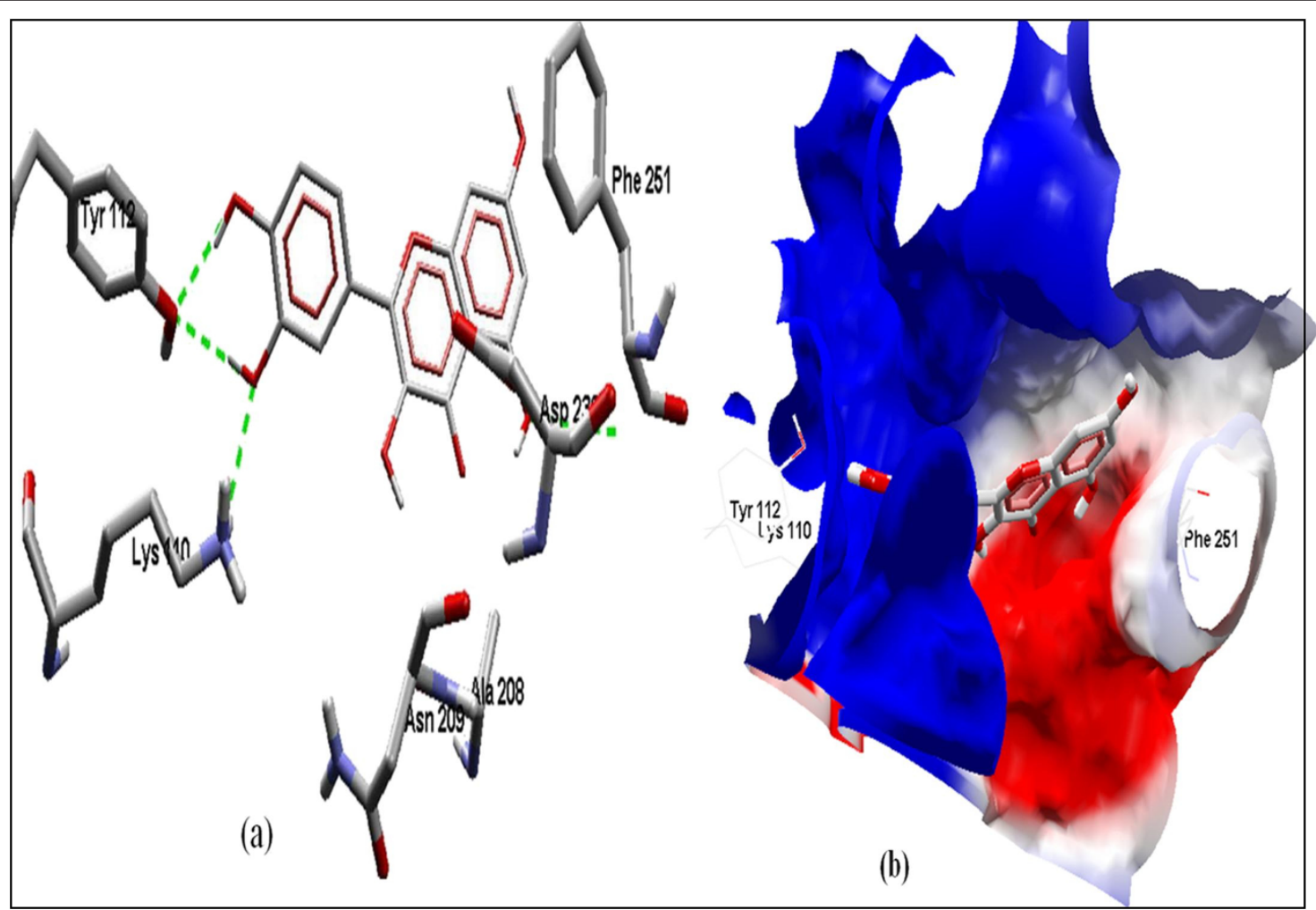

Figure 8 Docked conformation of hydrogen bonding view and 8.b with Electrostatic interaction of Quercetin with interacting amino acids of human NADH-cytochrome b5 reducatse protein at the active site cavity.

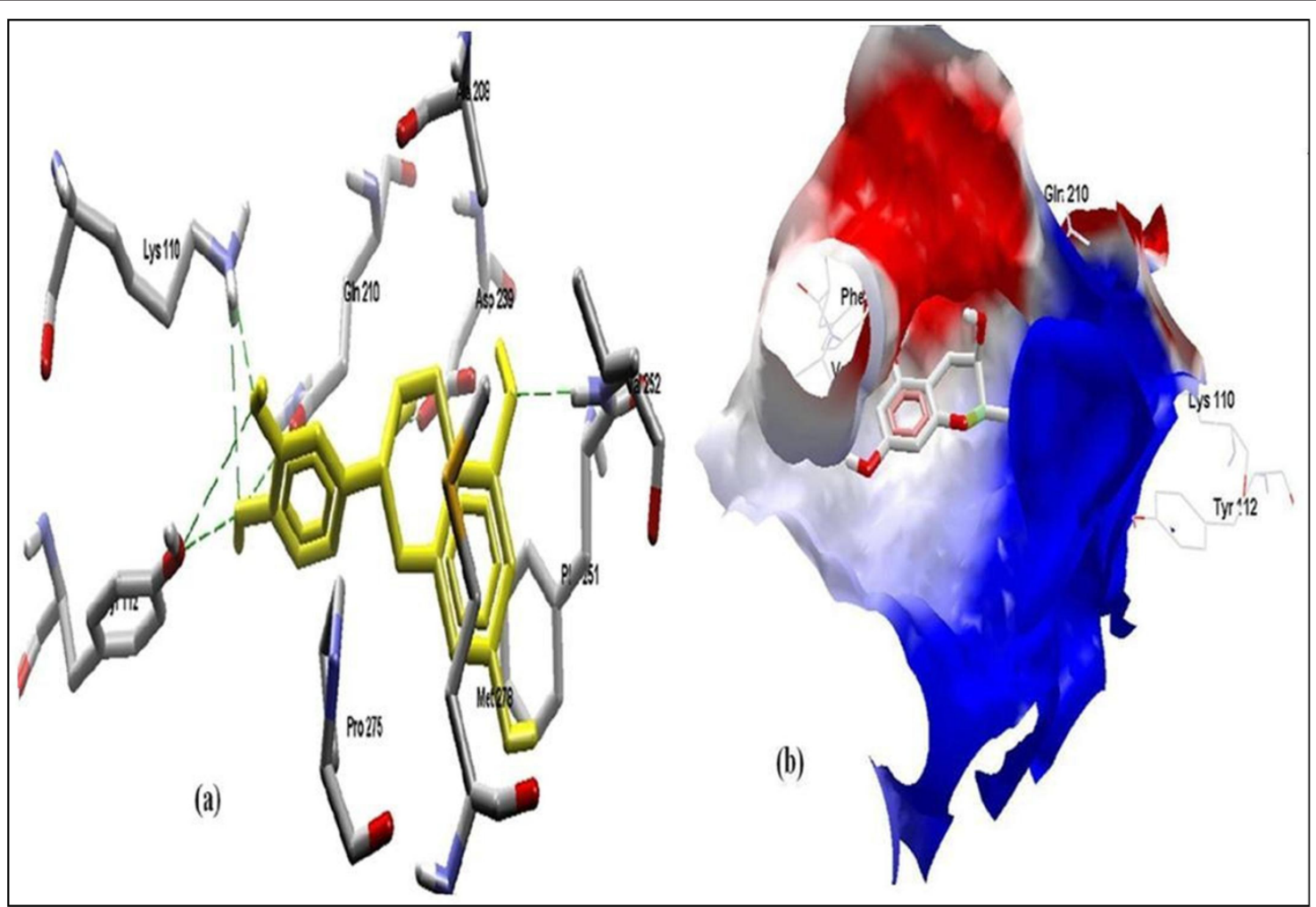

Figure 9 Docked conformation of hydrogen bonding view and 9.b with Electrostatic interaction of Epicatechin with interacting amino acids of human $\mathrm{NADH}$-cytochrome $\mathrm{b} 5$ reducatse protein at the active site cavity. 


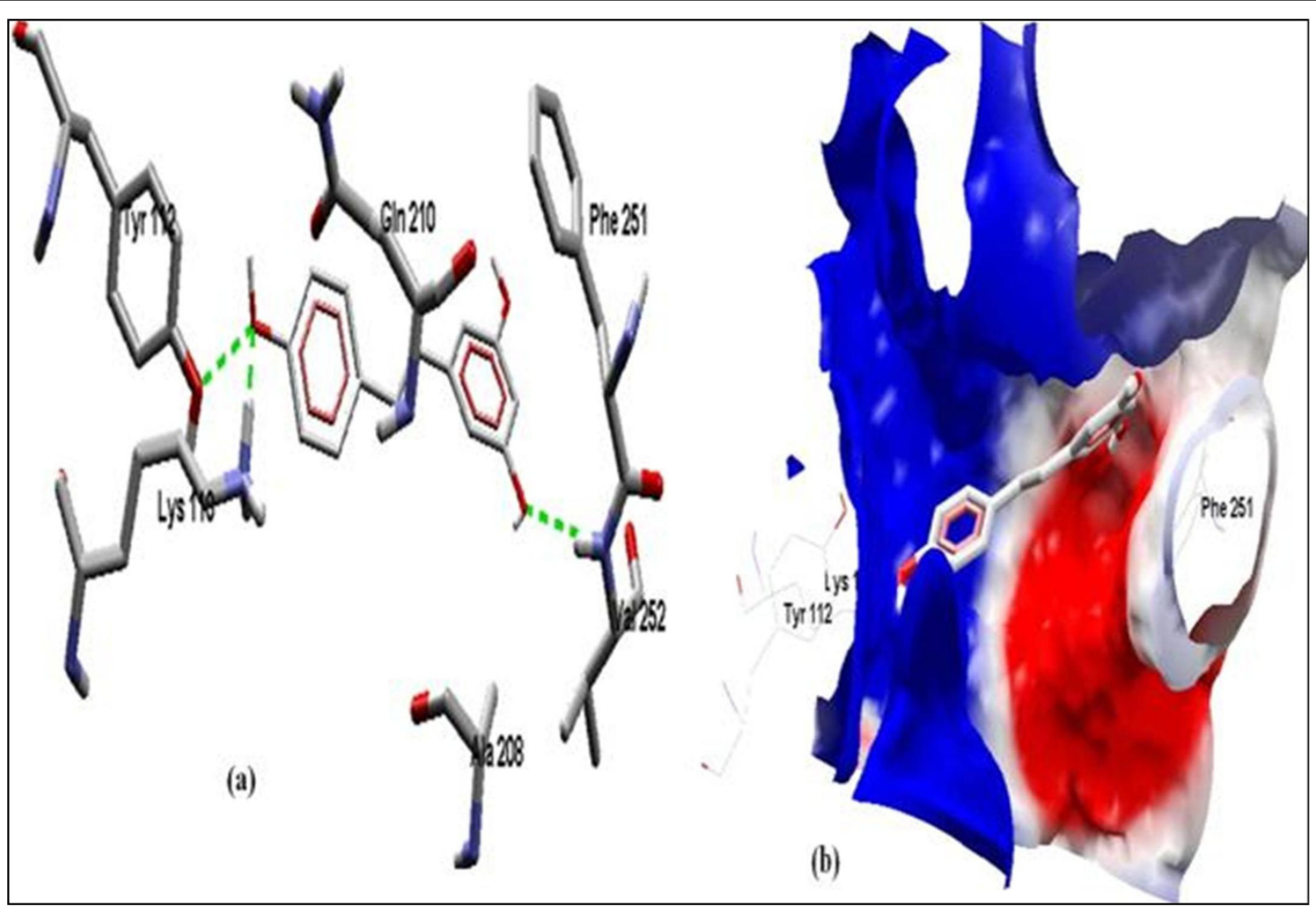

Figure 10 Docked conformation of hydrogen bonding view and 10.b with Electrostatic interaction of Resveratrol with interacting amino acids of human NADH-cytochrome b5 reducatse protein at the active site cavity

minimum common pharmacophoric features in all the selected polyphenols proves the wet lab findings [12,13] which show that these polyphenols have the ability to interact and donate protons to the Human NADH-cytochrome b5 reductase.

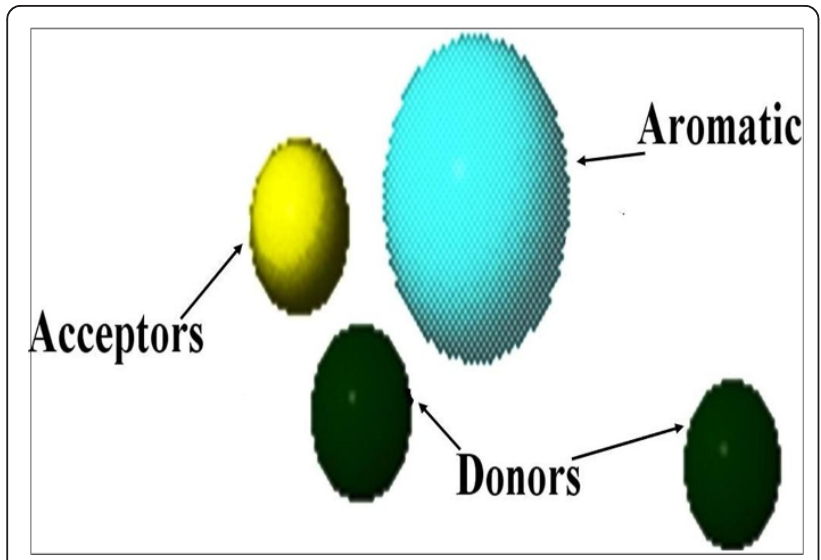

Figure 11 Derived Common pharmacophoric features for all the selected polyphenols (NADPH, beta-NADH, EGCG, Quercetin, Catechin, Epicatechin, Resveratrol and FAD) using PharmaGist sever.

\section{Conclusion}

Given the importance of human PMRS system during human aging and life span determination [8,9,22], our findings provide important insight into the docking and binding characteristics of the selected polyphenols on the Human NADH-cytochrome b5 reductase. With the help of these comparative results for docking simulation and pharmacophoric features, molecules having higher electron donor/acceptor efficacy for activation of the PMRS system can be designed. It is significant that activation of PMRS is being viewed as a putative mechanism for designing anti-aging agents [14]. Our in silico study may also lead to important information regarding the use of polyphenols as immunomodulating agents.

\section{Abbreviations}

EGCG: Epigallocatechin gallate; PMRS: Plasma membrane redox system.

\section{Acknowledgements}

One of the authors (RKK) gratefully acknowledges the Director, IIIT, Allahabad for providing necessary facilities for carrying out the computational work.

\section{Author details}

'Division of Applied Science \& Indo-Russian Center For Biotechnology [IRCB], Indian Institute of Information Technology, Allahabad 211012, India

${ }^{2}$ Department of Bioinformatics, UIET, CSJM University, Kanpur 208024, India 
${ }^{3}$ Department of Biochemistry, University of Allahabad, Allahabad 211002, India

\section{Authors' contributions}

RKK carried out docking simulation study, DVS performed pharmacophoric study, KM supervised docking and pharmacophoric studies, and SIR conceived the study, drafted the manuscript. All authors read and approved the final manuscript.

\section{Competing interests}

The authors declare that they have no competing interests.

Received: 17 December 2011 Accepted: 4 April 2012

Published: 4 April 2012

\section{References}

1. Orringer EP, Roer ME (1979) An ascorbate mediated transmembrane reducing system of the human erythrocytes. J Clin Invest 63:53-58. doi:10.1172/JCl109277.

2. Greibing C, Crane FL, Low H, Hall K (1984) A transmembranous NADH dehydrohgenase in human erythrocyte membranes. J Bioenerg Biomembr 16:517-533. doi:10.1007/BF00743243.

3. Kilberg MS, Christensen HN (1979) Electron transferring enzymes in the plasma membrane of the Ehrlich ascites tumor cell. Biochemistry 18:1525-1530. doi:10.1021/bi00575a021.

4. Crane FL, Sun IL, Clark MG, Grebing C, Low H (1985) Transplasma membrane redox systems in growth and development. Biochim Biophys Acta 811:233-264

5. Rubinstein B, Luster DG (1993) Plasma membrane redox activity: components and role in plant processes. Ann Rev Plant Physiol Plant Mol Biol 44:131-155. doi:10.1146/annurev.pp.44.060193.001023.

6. Herst PM, Berridge MV (2006) Plasma membrane electron transport: a new target for cancer drug development. Curr Mol Med 6:895-904. doi:10.2174/ 156652406779010777.

7. Ly JD, Lawen A (2003) Transplasma membrane electron transport: enzymes involved and biological function. Redox Rep 8:3-21. doi:10.1179/ 135100003125001198.

8. Rizvi SI, Jha R, Maurya PK (2006) Erythrocyte plasma membrane redox system in human aging. Rejuvenation Res 9:470-474. doi:10.1089/ rej.2006.9.470

9. Rizvi SI, Pandey KB, Jha R, Maurya PK (2009) Ascorbate recycling by erythrocytes during aging in humans. Rejuvenation Res 12(1):3-6. doi:10.1089/rej.2008.0787

10. Rizvi SI, Srivastava N (2010) Erythrocyte plasma membrane redox system in first degree relatives of type 2 diabetic patients. Int J Diab Mellitus 2:119-121. doi:10.1016/.jijdm.2010.05.005.

11. Correll CC, Batie CJ, Ballou DP, Ludwig ML (1992) Pthalate dioxygenase reductase: a modular structure for electron transfer from pytidine nucleotides to [2Fe-2S]. Science 258:1604-1610. doi:10.1126/ science.1280857.

12. Rizvi SI, Pandey KB (2011) Activation of the erythrocyte plasma membrane redox system by resveratrol: a possible mechanism for antioxidant properties. Pharmacol Rep 62(4):726-732

13. Rizvi SI, Jha R, Pandey KB (2010) Activation of erythrocyte plasma membrane redox system provides a useful method to evaluate antioxidant potential of plant polyphenols Methods Mol Biol 594:341-348

14. Rizvi SI, Jha R (2011) Strategies for the discovery of anti-aging compounds. Expert Opin Drug Dis 2011, 8(1):89-102

15. Thomsen R, Christensen MH (2006) MolDock: a new technique for highaccuracy molecular docking. J Med Chem 49(11):3315-3321. doi:10.1021/ jm051197e.

16. Friesner RA, Murphy RB, Repasky MP, Frye LL, Greenwood JR, Halgren TA, Sanschagrin PC, Mainz DT (2006) Extra precision glide: docking and scoring incorporating a model of hydrophobic enclosure for protein-ligand complexes. J Med Chem 149(21):6177-6196

17. Schneidman-Duhovny D, Dror O, Inbar Y, Nussinov R, Wolfson HJ (2008) Deterministic pharmacophore detection via multiple flexible alignment of drug-like molecules. J Comput Biol 15(7):737-754. doi:10.1089/ $\mathrm{cmb}$.2007.0130.
18. Bando S, Takano T, Yubisui T, Shirabe K, Takeshita M, Nakagawa A (2004) Structure of human erythrocyte NADH-cytochrome 5 reductase. Acta Cryst 60(11):1929-1934

19. Dutta S, Burkhardt K, Swaminathan GJ, Kosada T, Henrick K, Nakamura H, Berman HM (2009) Data Deposition and Annotation at the Worldwide Protein Data Bank. Mol Biotechnol 42(1):1-13. doi:10.1007/s12033-008-91277.

20. Jacobson MP, Pincus DL, Rapp CS, Day TJ, Honig B, Shaw DE, Friesner RA (2004) A hierarchical approach to all-atom protein loop prediction. Proteins 55(2):351-367. doi:10.1002/prot.10613.

21. Albers HMHG, Hendrickx LJD, van Tol RJP, Hausmann J, Perrakis A, Ovaa $H$ (2011) Structure-based design of novel boronic acid-based inhibitors of autotoxin. J Med Chem 54(13):4619-4626. doi:10.1021/jm200310q.

22. Rizvi SI, Kumar D, Chakravarti S, Singh P (2011) Erythrocyte plasma membrane redox system may determine maximum life span. Medical Hyp 76(4):547-549. doi:10.1016/j.mehy.2010.12.014.

doi:10.1186/2191-2858-2-12

Cite this article as: Kesharwani et al: Plant polyphenols as electron donors for erythrocyte plasma membrane redox system: validation through in silico approach. Organic and Medicinal Chemistry Letters 2012 2:12.

\section{Submit your manuscript to a SpringerOpen ${ }^{\circ}$ journal and benefit from:}

- Convenient online submission

- Rigorous peer review

- Immediate publication on acceptance

- Open access: articles freely available online

- High visibility within the field

- Retaining the copyright to your article

Submit your next manuscript at $\gg$ springeropen.com 